\title{
Discussion/What Do These Findings Tell Us
}

\begin{abstract}
In this chapter we present the empirical data and organise them in such a way that can be used to improve our understanding of what over 50s have learned at work, what skills they have developed and how they have found their age and experience to be an advantage in carrying out their working tasks.
\end{abstract}

Keywords Competence $\cdot$ Experience $\cdot$ Learning

\subsection{Introduction to Discussion}

Here we analyse the findings and group them in such a way that can be used to improve our understanding of what over 50 s have learned at work, what skills they have developed and how they have found their age and experience to be an advantage in carrying out their working tasks. In this way we hope to develop a basis upon which we can discuss the concept of senior competence. The categories which have emerged from our analysis of the data are communication, confidence, understanding of context, and a group of abilities which we have classified as variety, such as variety of workplaces, tasks, colleagues and methods or ways of doing things. We have also identified a category which we have called seeing the big picture and lastly, we include a more general category which we have called maturity. These categories may not cover all our findings and are

(C) The Author(s) 2021

69

A. I. Hilsen and D. S. Olsen, The Importance and Value of Older

Employees, https://doi.org/10.1007/978-981-16-2861-0_6 
probably not an exhaustive description of what seniors know, however the categories provide us with a variety of lenses through which we can view our findings and reflect upon what the data tells us in order to make sense of it. Many of the cases illustrate more than one category, and we have chosen the examples discussed in this chapter based on the lens through which we are viewing it.

\subsection{CommunicATION}

The interviewees were not asked directly about communication, or how they had learned to communicate, but in the course of the interviews we observed several examples of situations where they demonstrated clear abilities to use language, tone, choice of words and body language to communicate. For example, several interviewees explained how challenging it was to explain the complexity of new regulations before they were operationalised. There was one example of an employee in a government department who had considered this was conscious of her own abilities as an experienced communicator. As she said:

... when you are out there at a site talking to an expert, you just have to try different ways of talking and find out what works. Experts are experts, whatever their field. You have to talk to them in the right way.

This suggests an awareness of what is the right way of communicating.

One interviewee described how her experience working with lawyers had made her aware of the different ways in which one can talk about the same themes. She became more aware of this difference when she worked on historical and cultural issues. The different groups of employees communicated in different ways and stressed different things and presented information to others in different formats and used different words. Again, a clear awareness, not only of the importance of communication, but also how communication can be used to work with different groups. The latter example is interesting because the interviewee linked her current understanding to her own varied career path and to her own development over time.

These reflections suggest that this experienced employee had developed a kind of translator ability, whereby she considers the receiver of the information first, then decides how she will present the information. 
Some of the other examples suggest that something similar is happening, although employees may not be aware of what they are doing, such as the nurse who knows exactly what to say and how to say it, in order to calm patients. This was not only an act of compassion, but also improved the efficiency of the task and made the job easier.

Sharing information with younger colleagues is also an important, but perhaps little recognised skill found among older employees. One of the examples from the hospital case illustrates this quite well, where an older employee remembered how her older colleague communicated a sense of security.

One of the government employees mentioned talking about communication to new recruits. The younger employees were used to communicating in sound bytes, i.e. short summarised pieces of digital information. The older employees, on the other hand, had spent years honing their skills at report writing. They claimed they could communicate complex information to multiple readers in an unambiguous way without causing offence to any group. They were ready and willing to share this information with their colleagues.

\subsection{CONFIDENCE}

"Confidence is a belief in oneself, the conviction that one has the ability to meet life's challenges and to succeed-and the willingness to act accordingly. Being confident requires a realistic sense of one's capabilities and feeling secure in that knowledge", according to Psychology Today (https://www.psychologytoday.com/intl/basics/confidence).

Our interviewees tell us about several factors that contribute to what we perceive as their feeling of confidence. They talk about being competent in their jobs, but also about being confident in life. They talk about being in a phase of life where they are more relaxed, more tolerant and accepting of others.

This confidence is not only of benefit in doing their jobs, but can also help and support younger colleagues. One informant talked about when she was younger and new in her job at the hospital, how much more secure she felt when she worked with colleagues with long experience. Being with someone who was experienced in the job added to her feeling of security, so when she needed to consult she appreciated the older, more experienced colleague. 
Confidence, as described by our interviewees, is also based on feeling competent at a high level. Not only knowing how to do your job, but being able to act fast in a situation, whereas younger colleagues need to "do it by the book" and think about how to act. This very much reflects the learning process described by Dreyfus and Dreyfus (1986), where the learned moves through the steps from Novice, to Advanced Beginner, Competence, Proficiency and Expertise. According to Dreyfus and Dreyfus: "The beginning student wants to do a good job, but lacking any coherent sense of the overall task he judges his performance mainly by how well he follows learned rules. After he acquires more than just a few rules, the exercise of his skill requires so much concentration that his capacity to talk or listen to advice is severely limited. Like the training wheels on a child's first bicycle, these rules allow the accumulation of experience, but soon they must be put aside to proceed" (Dreyfus \& Dreyfus, 1986: 22).

This is reflected in how our older workers talk about younger colleagues and their need to "go by the book". Over time they talk about older workers having developed to a stage where they know how to do things without having to refer to any specific manual or think about why and how to perform a job operation. They have become proficient at their jobs. As described by Dreyfus and Dreyfus: "As events modify the salient features, plans expectations, and even the relative salience of features will gradually change. No detached choice or deliberation occurs. It just happens, apparently because the proficient performer has experienced similar situations in the past and memories of them trigger plans similar to those that worked in the past and anticipations of events similar to those that occurred" (Dreyfus \& Dreyfus, 1986: 28).

Our interviewees described situations where they "just knew how to act" without having to consciously think about it. They talked about having the competence and confidence to do their work, whether that was as nurse, cleaner or inspector, because they had age and experience. The example of the cleaner who felt secure enough in her job to not feel intimidated by doctors she had first met when they were interns, shows that confidence is also dependent on age and long work career. We were told the same story from the older inspectors who had the confidence to do their job, as they knew it should be done, in difficult situations. 
In many ways we could say that the late career competence described by our interviewees seems to reflect a high degree of confidence in being able to cope at work and a sense of their job situation being comprehensible to them; they know what to do, how to do it and why it should be done in this way. They experience the demands of the job are manageable and they believe the job they do is meaningful. Coping at work is dependent of several factors, both personal/individual and contextual/environmental, where the environment includes physical surroundings as well as social demands/support (Daatland \& Solem, 2011: 99). Coping is often seen as a personality trait, as exemplified by the concept of self-efficacy (Bandura, 1997) or sense of coherence (Antonovsky, 1985). Although such traits are often seen as fairly stable over the lifetime, both Bandura and Antonovsky accept that they can change over time. The concepts are dynamic, which indicates that they are open to change.

Antonovsky's sense of coherence (SOC) consists of three components: comprehensibility, manageability and meaningfulness. Does the individual perceive the situation one finds oneself as comprehensible, is it manageable and is it meaningful? The SOC is defined as: "The extent to which one has a pervasive, enduring though dynamic, feeling of confidence that one's environment is predictable and that things will work out as well as can reasonably be expected" (Antonovsky, 2002: 128; 2000: 37). Antonovsky developed his concept through studies of people who, in spite of having been through horrible ordeals, such as Holocaust survivors, maintained a feeling of positive health. A strong SOC is Antonovsky's answer to the question of what makes a person more likely to feel less stress and tension, and to believe that he or she can meet demands.

Late career competence as described by our interviewees reflects a high degree of confidence in being able to cope and meet the demands of their jobs. They also have the confidence to accept that they sometimes make mistakes. Based on experience and age, they know-how to do their jobs and can reflect on why they do it the way they do, and they talked about the need to be constantly learning through practice and reflection.

\subsection{Understanding of Context}

What is the context of this experience-based knowledge, this late career competence of older workers? The competence is connected to an understanding of context, as they all talk about their competence in a specific 
workplace context or setting, performing activities that are meaningful given the context of the type of work they do. The older workers in our cases talk about long experience has taught them how to do their job with expertise, they talk about carrying the history of the workplace, being tradition bearers, knowing how and why things were done differently in the past and even having practical knowledge (such as referring to physical features of the workplace) acquired having worked in the same workplace for many years. They are tuned in to the local environment and know who to go to if they have questions (know-who). They not only see their own place and contribution in the workplace but they also demonstrate awareness of colleagues' needs and abilities and talk about caring and sharing with their younger colleagues.

Context and setting are two related concepts, still we understand them as referring to separate phenomena. Settings refer to where something happens. As defined by the WHO (in the Ottawa Charter, 1986): "Health is created and lived by people within the settings of their everyday life; where they learn, work, play and love" (WHO, 1986: 3-4). The field of health promotion has adopted the settings approach, where things not only happen in a setting, but you could also strive to make the setting supportive of promoting health, the so-called settings approach of working with a setting (Schriven \& Hodgins, 2012). Settings from this perspective is where your life is lived, in a fairly physical/spatial meaning. We talk about worklife, or even more specific the workplace, as settings where our older workers perform their work. Late career competence is played out in the workplace settings specific to the jobs they have.

Context is a more complex phenomenon. Context can refer to the physical surroundings, but not in a purely objective sense. According to Bateson (1972: 186), contexts, and his connected concept of frames, are psychological concepts. They are concepts by which we organise and understand phenomena. Contexts can be used to describe fields of learning, as Guile (2006) talks about learning across the contexts of vocational curricula and workplace practice. His agenda is to conceptually bridge the gap between theory and practice in vocational/professional education, in order to develop an understanding of learning across the different contexts. Theories on learning tend to use context in many, and sometimes conflicting, ways (Dohn et al., 2018). Do we learn in a context or is the context the theoretical framework for understanding learning, as the examples of historical, cultural, social or national contexts for learning (ibid.: 1-2). 
When we explore late career competence in the workplace as having given the older workers an understanding of context, we intentionally use the concept in both an empirical and theoretical sense. In an empirical sense, they understand and describe their competence, as competent practice in the performance of their work, with practical examples of situations and performances. In a theoretical sense, more in line with Bateson's understanding of context as a psychological concept (Bateson, 1972), they describe their competence as an understanding of their role and relationship to co-workers. As older workers they not only understand their own job and what it takes, but they talk about being aware of colleagues' needs and abilities. From this understanding also comes their examples of caring and sharing with their younger colleagues. Age not only gives experience; it also gives maturity. As one interviewee explained: "I'm more tolerant as a grandmother than I was as a mother". The ability to care for co-workers can be understood as a reflection of their understanding of context, not only in a practical, physical way, but also as a relationship with mutual dependence.

\subsection{VARIETY}

The longer the working career, the more we would expect the employee to have experienced. Over time many of them experience more of the same, while others amass a variety of different experiences. We found this idea of variety an interesting aspect of the long working career and chose to look more closely at how our interviewees experienced this and how it was useful for them.

One form of variety we identified, was having worked for different employers or having worked at different locations for the same employer. We would expect that this kind of mobility would have exposed employees to different forms of management, different challenges and different ways of dealing with these challenges. We would also expect that the employee would have met more people and perhaps have a larger network of contacts, than an employee who had remained at the same place throughout his or her career.

In one interview the "irreplaceable" project manager said that she had learned to "manoeuvre through the state system in different situations" always knew who to ask for help. Her network extended across several government departments where she had previously worked and included people with a wide variety of expertise. She actively maintained this 
network and even attended conferences outside her own area of expertise, with the aim of keeping herself up-to-date on what was happening in other areas, knowing who knew what and might be able to help her in the future. She had not really considered this to be a particular advantage until we interviewed her, it had just been the way she was used to working. Looking back on her she said she could see that it had been an advantage and made it easier for her to take chances, like daring to lead a project on new technology, daring to apply for a new position she was not sure she was qualified for.

Another example was a project manager who had worked on many different projects. He had worked within the public and the private sector and worked in several different departments in the public sector. $\mathrm{He}$ described how he always took what he had learned in earlier projects with him into new projects. When asked about the advantages this gave him, he described how he viewed new projects as icebergs, i.e. the largest part was hidden. He knew, almost instinctively, what questions to ask and where to dig for information and find potential weaknesses.

Another form of variety which emerged from interviews was variety in working tasks. This kind of variety was something which can affect those who remain in the same position and at the same location throughout their working career, but also those who move from one function to another. There are examples in the interview material of employees whose experience has made it possible for them to do the same task in different ways, or to experience doing a task with and without technology. Some of the benefits of varied ways of working were quite subtle, such as having multiple choices to consider when taking a decision or solving a problem. As one interviewee said, he no longer takes the first potential solution, he looks for the best.

An example of this can be seen in the interviewees who did not want to go on courses to learn new ICT systems, instead they chose to learn by trial and error or by asking colleagues. These employees were aware of the course they could have attended and there were no particular obstacles to their participating in organised training courses. They had, however, experienced new ICT systems before. They had also experienced doing the job manually, with little ICT support. This broad experience of different ways of working with technology and different ways of learning about technology provided them with choices. The advantage they mentioned was that they did not need to waste time on a 3-day course, what they 
learned was what they needed in order to do their work, not lots of other unnecessary technological functions.

We have also mentioned the example of a surgeon who was familiar with the traditional way of operating on an aortic aneurism as well as the more modern and simpler treatment of inserting stents. Younger colleagues were not educated in the traditional method and therefore it was not natural for them to recommend it or even to see it as an option for patients. The older surgeon however believed that his experience gave him more options in choosing the best treatment for his patient.

Another example of alternative ways of doing things can be seen in some of the examples where employees talked about a new standardised electronic archive system. They all understood the importance of classifying and storing government documents and had long experience of doing this and of finding (or not finding) documents. They did not contest the archiving system directly, what they reacted to, was the imposition of best practice. They considered that their long experience in the department had provided them with a wealth of experience and believed that their methods might in fact be the "best practice". Had they not had all this experience, they conceded that they would probably just have accepted the new system unaware that there were alternative ways of archiving.

\subsection{Seeing the Big Picture}

We have discussed how many experienced older employees can see alternative ways of doing things and have multiple interpretations of the same information, however we also found examples where relatedness and the ability to connect was considered valuable. One example was the nurse who talked about the "fresh ones" who were unable to see the relationship between all the different elements in the patient's treatment. For her, it was natural to see all these connections and she maintained that this made her work much more efficient, she could jump faster from one step to the next instead of plodding through all the basic steps.

In another example the inspectors checking on safety and security described how they began to form an opinion of the standards as soon as they entered the reception. In order to carry out a formal evaluation of a client, the inspectors must follow strict guidelines, but this example suggests that other criteria can influence the way in which the evaluation progresses. What the inspectors saw in the reception was not an alternative 
to what they found in the formal evaluation, but it was viewed as supplementary information which prepared them to look more carefully in the next phase. Their long experience told them that clients who received a critical evaluation of their security and safety often had a messy reception. They had identified a relationship between two situations, a relationship that turned up time and again. Noticing these small details and comparing them to past experiences was considered an advantage and the inspectors thought it made their evaluation more effective.

\subsection{Maturity}

In the interviews and discussions, we have heard many mentions of the mature worker and maturity as an aspect of being an experienced older worker. Maturation can be used to describe the process of reaching a stage of full or advanced development (Dictionary.com). Given such an understanding of maturity, it is obvious that mature workers have had years of experience and learning to facilitate the process of maturation.

Maturity also lends the individual authority in the sense of being listened to and having one's communications respected. Both the hospital workers and the inspectors talk about how age and experience have given them authority in their daily work. Whether it is the case of interacting with colleagues and patients in a hospital or with companies/organisations in their role as inspectors, the mature worker carries a combination of charisma and clout, of authority, when interacting with others. When describing the mature worker, several interviewees used the word "pondus". "Having pondus" in the sense of weight, importance, significance. The simple translation of pondus from latin is weight (physical), but it can also be used in transferred meaning. In addition, we find pondus used to mean important, significant, as in the sentences: "Cur tam magnum habet pondus "splendor veritatis"? (Why is the "splendour of truth" so important?), or "Anni iubilaris habita ratione, magnum pondus habere debebat Congressus Eucharisticus Internationalis". In the spirit of this Jubilee Year the International Eucharistic Congress was intended to have special significance (vatican.va at https://glosbe.com/la/en/ pondus). In Norwegian the word pondus is widely used, both in its physical meaning (being big, heavy) and its transferred meaning as having clout, authority, being listened to and respected. Our mature workers acknowledge that age and experience have given them this authority, 
this pondus, and they experience situations where it has made their work easier.

Maturity describes the result of age and experience for the individual who has been open to learning and reflection throughout one's career. At the same time, the concept of maturity may hide the importance of the environment where this process has taken place. Maturity consists of more than age. When talking about mature wines or cheese, we don't just talk about old wine and cheese; we talk about refined products. Old wine can turn to vinegar and mouldy cheese is not an ideal unless you are a gorgonzola. They are refined as a result of the process they have been through. Stimulants have been added (bacterial cultures when it comes to cheese), storage facilities have been controlled and the process of maturation has been closely watched by the producers.

According to the Milk Quality Improvement Program at Cornell University (www.milkfacts.info): "There is a wide variety of bacterial cultures available that provide distinct flavor and textural characteristics to cheeses. (...) Even yeasts and molds are used in some cheeses to provide the characteristic colors and flavors of some cheese varieties. Torula yeast is used in the smear for the ripening of brick and limburger cheese. Examples of molds include Penicillium camemberti in camembert and brie, and Penicillium roqueforti in blue cheeses".

In a (fairly) similar manner mature workers are the result of a process where learning and experiences have been added over years, stimulants have been added as they received feedback from managers, colleagues and users, and they have developed in a work environment that not only hinders damage and disease, but provides a basis for a healthy and meaningful working situation.

\subsubsection{What Have We Learned from This Analysis?}

The interviews provided many examples where interviewees, unprompted, described their learning experiences. Highly qualified workers taking master's degrees in management at $\mathbf{5 5}$ and over, while others were learning new languages in their free time. There was a high level of awareness of the value of knowledge and the importance of continually developing it.

Some of the findings provide examples of what we define as the added advantages of age or maturity. Characteristics which can best be described as a mix of charisma and clout are attributed to the mature worker, 
the older worker. The older workers tell us about authority in situations where they are respected and listened to differently from younger colleagues. Where users of the services, such as patients or children might feel insecure, the mature worker can create a feeling of safety and provide emotional support in addition to their normal tasks.

Some characteristics were associated with age, such as what stage of life you are at, understanding society, values and attitudes that characterise the present generation of older workers, and age-specific references (being of the same age as the people with whom you interact and recognising the same stories or references). Older workers are in the latter part of their working career and might not be as ambitious and driven by the need to get promotion as younger workers might. Some talked about being more concerned by what they left behind when they retired than in "building a career". This was viewed as making them more generous in sharing knowledge and experience. Not only being a resource and support for their younger colleagues, but they could also be non-threatening to managers. One young manager said she relied on her oldest employees, as they were less interested in making careers for themselves and therefore more willing to share and support her when she asked.

The findings tell us of a wide array of advantages based on length of career and age. There are advantages for the older employee as well for their younger colleagues. Being competent in their jobs, having knowledge and experience to draw on and the maturity of age is an advantage for the older workers in performing their jobs, as described by several of our interviewees. It also makes these mature workers valuable as coworkers for younger and less experienced colleagues. In this way, there are also advantages for the enterprise as a whole. Mentoring, shadowing and mixed-age teams are all ways of using the complementary competence of younger and older workers to the advantage of the enterprise.

\section{REFERENCES}

Antonovsky, A. (1985). Health, stress, and coping. San Francisco: Jossey-Bass Publishers.

Antonovsky, A. (2000). Helbredets mysterium. Hans Reitzels Forlag.

Antonovsky, A. (2002). Unravelling the mystery of health: How people manage stress and stay well. In D. F. Marks (Eds.), The health psychology reader (pp. 127-139). Sage. 
Bandura, A. (1997). Self-efficacy: The exercise of control. W H Freeman/Times Books/Henry Holt \& Co.

Bateson, G. (1972). Steps to an ecology of mind. Ballantine Books.

Daatland, S. O., \& Solem, P. E. (2011). Aldring og samfunn (2nd ed.). Fagbokforlaget.

Dohn, N. B., Hansen, S. B., \& Klausen, S. H. (2018). On the concept of context. Edu. Sci, 8, 111. https://doi.org/10.3390/edusci803111. www. mdpi.com/jpornal/education.

Dreyfus, H. L., \& Dreyfus, S. E. (1986). Mind over machine: The power of human intuition and expertise in the era of the computer. Oxford: Basil Blackwell.

Guile, D. (2006). Learning across contexts. Educational Philosophy and Theory, 38(3), 251-268. https://doi.org/10.1111/j.1469-5812.2006.00193.x.

Schriven, A., \& Hodgins, M. (2012). Health promotion settings: Principles and practice. Sage.

The Milk Quality Improvement Program, Cornell University, USA. Downloaded September 15th, 2020 from http://www.milkfacts.info/Milk\%20Processing/ Cheese\%20Production.htm\#CAge.

WHO (World Health Organization). (1986). Ottawa Charter for Health Promotion. WHO.

Open Access This chapter is licensed under the terms of the Creative Commons Attribution 4.0 International License (http://creativecommons.org/licenses/ by $/ 4.0 /$ ), which permits use, sharing, adaptation, distribution and reproduction in any medium or format, as long as you give appropriate credit to the original author(s) and the source, provide a link to the Creative Commons license and indicate if changes were made.

The images or other third party material in this chapter are included in the chapter's Creative Commons license, unless indicated otherwise in a credit line to the material. If material is not included in the chapter's Creative Commons license and your intended use is not permitted by statutory regulation or exceeds the permitted use, you will need to obtain permission directly from the copyright holder.

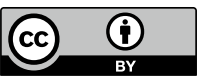

